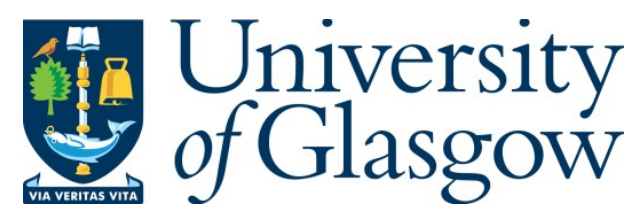

Gao, Z. and Huang, M. (2021) Effect of sample preparation method on mechanical behaviour of fibre-reinforced sand. Computers and Geotechnics, 133, 104007.

(doi: 10.1016/j.compgeo.2021.104007)

This is the Author Accepted Manuscript.

There may be differences between this version and the published version. You are advised to consult the publisher's version if you wish to cite from it.

https://eprints.gla.ac.uk/227608/

Deposited on: 7 January 2021

Enlighten - Research publications by members of the University of Glasgow http://eprints.gla.ac.uk 


\title{
Effect of sample preparation method on mechanical behaviour of
} fibre-reinforced sand

\author{
Zhiwei Gao ${ }^{1 *}$, Mian Huang ${ }^{1}$ \\ ${ }^{1}$ James Watt School of Engineering, University of Glasgow, Glasgow, G12 8QQ, UK \\ *Corresponding author. Tel: +44 1413303927; Email: Zhiwei.gao@glasgow.ac.uk
}

ABSTRACT: It is well known that the mechanical behaviour of pure sand is dependent on the internal soil structure, which can be affected by sample preparation methods. For fibre-reinforced sand (FRS), the sample preparation methods influence not only the internal structure of sand skeleton but also the distribution of fibre orientation and sand-fibre interaction. The effect of sample preparation methods on the mechanical behaviour of FRS has been investigated using comprehensive drained triaxial compression tests. The soil samples are prepared by moist tamping (MT) and moist vibration (MV). There is a small difference in the stress-strain relationship of pure sand with different sample preparation methods. But the response of FRS is dramatically different. Under the same initial conditions of void ratio, confining pressure and fibre content, FRS prepared using the MV method shows $30-50 \%$ higher peak deviator stress and much less dilative response. A newly developed constitutive model is used to simulate the stress-strain relationship of FRS prepared using different methods.

Keywords: Fibre-reinforced sand, moist tamping, dry vibration, constitutive model, critical state 


\section{INTRODUCTION}

The mechanical behaviour of saturated sand is affected by the internal structure (or fabric), which includes particle orientation, contact normal distribution and void space orientation (e.g., Ishihara, 1993; Yang et al., 2008; Sze and Yang, 2014; Gao et al., 2014). Such an effect is more visible in undrained tests because a small difference in soil dilatancy can cause a dramatic change in the excess pore water pressure and effective stress path. For fibre-reinforced sand (FRS), the stress-strain relationship is not only dependent on the structure of the sand skeleton but also the fibre distribution and sand-fibre interaction, which is affected by the sample preparation methods (Zornberg, 2002; Diambra et al., 2007; Ibraim et al., 2012).

Various methods have been used for preparing FRS samples in the laboratory. In Michalowski (1996), dry sand and fibres were dropped into the mould separately in five equal layers and then vibrated to reach the target density. Moist tamping (MT) is the most frequently used method for preparing FRS samples (Consoli et al., 2007; Ahmad et al., 2010; Ibraim et al., 2012; Kong et al., 2019). In this method, sand and fibres are first mixed at a certain water content to prevent segregation of fibres. The mixture is then deposited in the mould in several equal layers and compacted to a target density. This method has also been used in airfield construction using FRS (Santoni and Webster, 2001). The sample preparation method has a direct effect on the internal structure of the sand skeleton, fibre distribution and sand-fibre interaction. Consequently, the stress-strain relationship of FRS is affected by the sample preparation methods. But there is insufficient research in this regard. Ibraim et al. (2012) investigated the mechanical behaviour of loose FRS prepared using MT and moist vibration (MV) methods. While the dilatancy of FRS was found to be affected by the sample preparation methods, the shear stress-strain relationship was not. This could be attributable to the fact that the two methods create a similar distribution of fibre orientation in FRS samples (Ibraim et al., 2012). More research is thus needed to explore the mechanical behaviour of FRS with significantly different internal structures.

For practical applications, it is also important to characterise the mechanical behaviour of 
FRS with a proper constitutive model. But there is little research on how to model the effect of sample preparation methods on the stress-strain relationship of FRS. Some attempts have been made in modelling the fabric effect on the mechanical behaviour of pure sand (Yang et al., 2018; Zhao and Gao, 2016), where the difference in the initial sand fabric caused by the sample preparation methods is considered. The internal structure of FRS is affected by both the sand fabric and distribution of fibre orientation. Ibraim et al. (2012) used a model to describe the behaviour of FRS prepared using different methods in which only the soil fabric associated with the distribution of fibre orientation was considered. Since the sample preparation methods in that study were found to have a negligible influence on the shear stress and strain relationship of FRS, more research is needed to explore if this modelling assumption is proper when the effect of sample preparation methods is significant.

This study presents new research on the effect of sample preparation methods on the mechanical behaviour of FRS using a series of drained triaxial compression tests. The samples are prepared using MT and Moist vibration (MV) methods. Both the shear stress-strain relationship and dilatancy of FRS are found to be dramatically affected by the sample preparation methods. A newly developed multi-axial model for FRS is used to simulate the test results. Potential reasons for the difference in FRS behaviour are then discussed.

\section{Experiments}

\section{$\underline{2.1 \text { Materials and sample preparation methods }}$}

The Loksand ${ }^{\mathrm{TM}}$ fibres are used, with the properties being shown in Table 1 . The Leighton Buzzard sand is used as the host soil. Its properties are given in Table 2 and Fig. 1. The samples are prepared in a mould with $40 \mathrm{~mm}$ diameter and $80 \mathrm{~mm}$ length. Two sample preparation methods (MT and MV) have been used (Fig. 2). For both methods, sand and fibres are first mixed with a small amount of water (about $2 \%$ of the weight of dry sand) to prevent segregation of sand and fibres. Similar to the mixing process reported by Kong et al. (2019), all the samples are prepared in three layers. For the MT method, one third of the sand-fibre mixture is deposited into the mould for each layer (Fig. 2a). Extra water (about 9\% 
of dry sand weight) is then added to the mixture to lubricate the sand particles. Therefore, the water content of FRS samples prepared using MT is about $11 \%$ at the end of sample preparation. During the sample preparation, small vacuum pressure is applied to reduce the gap between the membrane and the mould (Fig. 3). Finally, vertical compaction is applied to achieve the required soil density for MT samples. When the samples are prepared using the MV method, no extra water is added, and the soil is compacted by applying fixed vertical load on the top and tapping on the side of the mould (Fig. 2b). Enlarged and lubricated end platens are applied to reduce the end constraint to the samples. The samples are flushed with $\mathrm{CO}_{2}$ after they are set up in the triaxial cell. Saturation is then carried out by increasing the back pressure, ensuring the $B$-value reaches at least 0.97 for each specimen.

Table 1: Properties of Loksand ${ }^{\mathrm{TM}}$ fibres

\begin{tabular}{ll}
\hline Parameter & Value \\
\hline Length & $35 \mathrm{~mm}$ \\
Diameter & $0.088 \mathrm{~mm}$ \\
Specific gravity $G_{f}$ & 0.91 \\
Tensile strength & $200 \mathrm{MPa}$ \\
\hline
\end{tabular}

Table 2: The properties of Leighton Buzzard Sand

\begin{tabular}{lc}
\hline Parameter & Value \\
\hline Specific gravity $\mathrm{G}_{\mathrm{s}}$ & 2.81 \\
Mean particle diameter $\mathrm{D}_{50}$ & $0.53 \mathrm{~mm}$ \\
Uniformity coefficient $\mathrm{C}_{\mathrm{u}}$ & 2.13 \\
Maximum void ratio $\mathrm{e}_{\max }$ & 0.86 \\
Minimum void ratio $\mathrm{e}_{\max }$ & 0.61
\end{tabular}




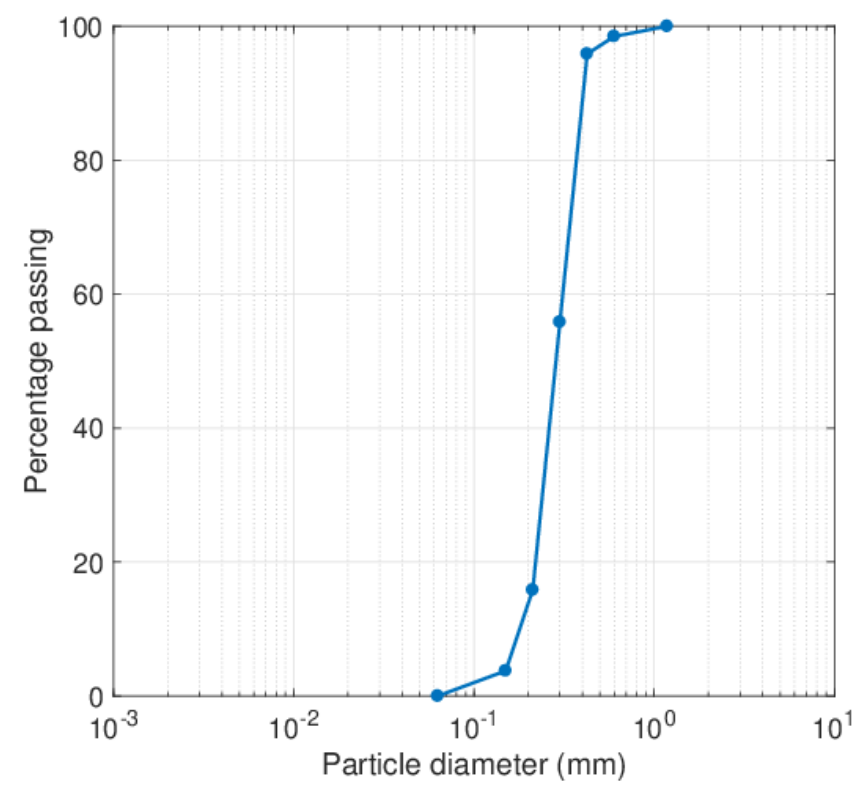

Fig. 1 Particle size distribution curve of Leighton Buzzard Sand

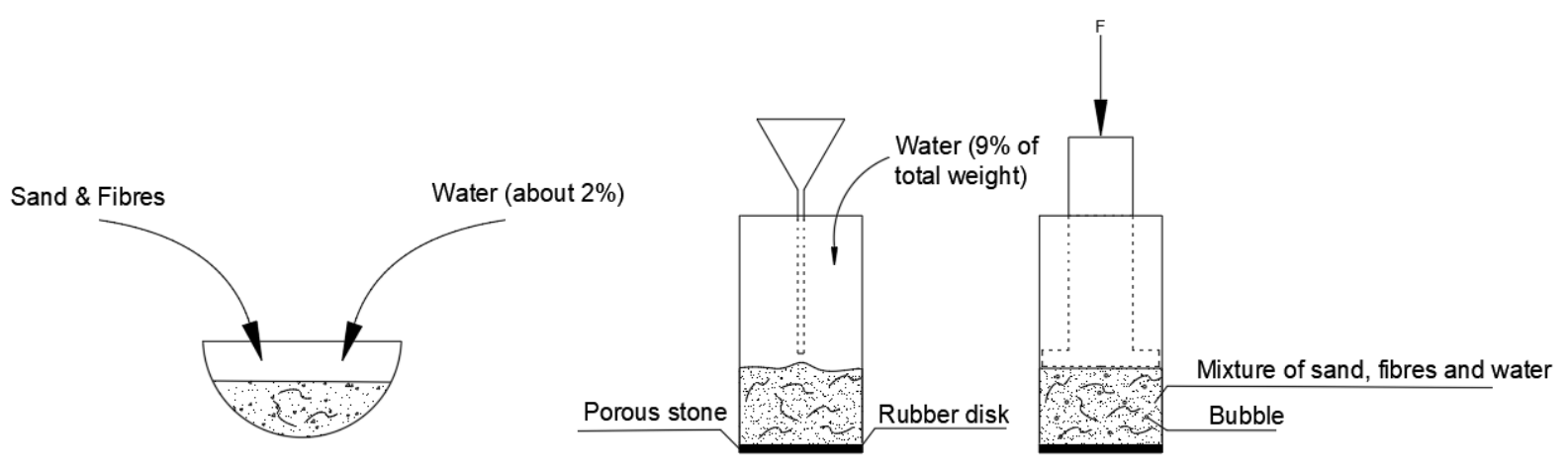

(a)

Sand \& Fibres Water (about 2\%)

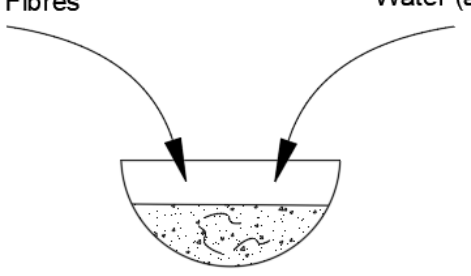

Porous stone
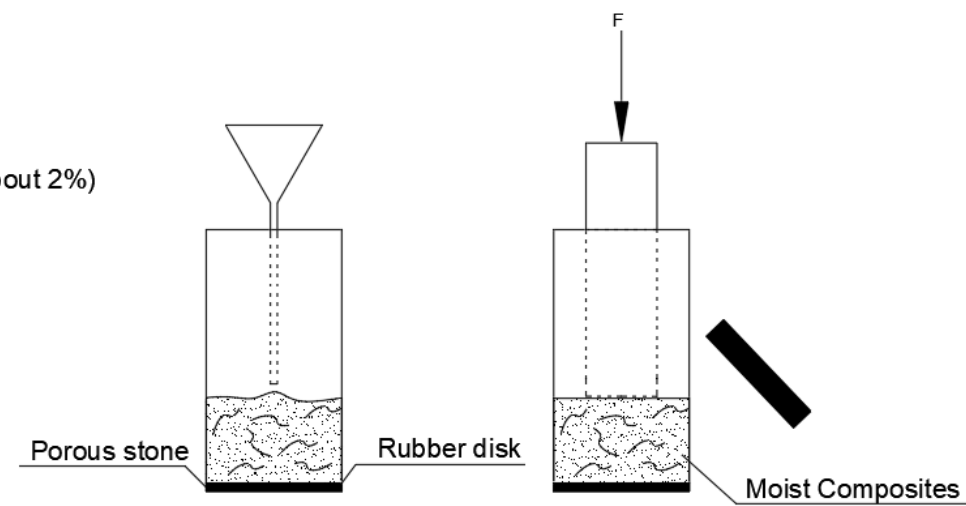

(b)

Fig. 2 Illustration of the sample preparation methods: (a) Moist tamping and (b) moist vibration 
Fig. 3 Application of suction be

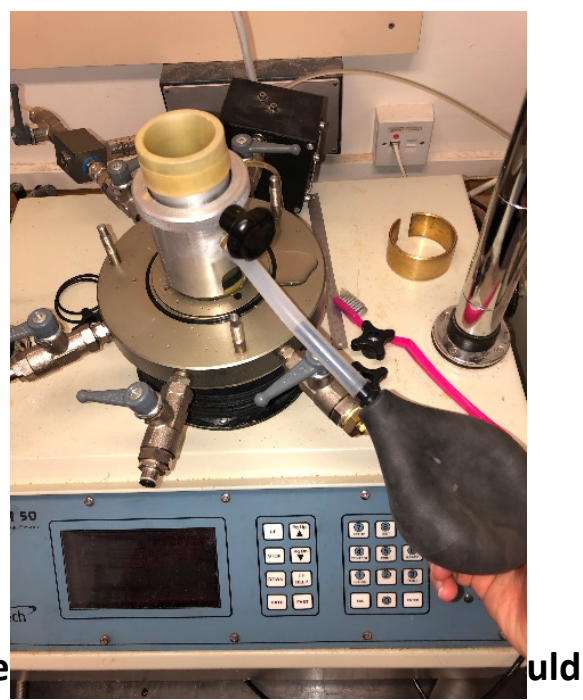

\subsection{Test results}

A total of 20 drained triaxial compression tests have been carried out for investigating the effect of sample preparation method on soil behaviour (Table 3). The initial void ratio e0, which is the void ratio at the beginning of triaxial compression, varies between 0.82 and 0.76 . The effective confining pressure $\sigma r$ is between $50 \mathrm{kPa}$ and $200 \mathrm{kPa}$ (Table 3 ). The fibre weight content $w f$ (ratio of fibre and dry sand weight) is $0.25 \%$. The repeatability of the tests is shown in Figs. 4 and 5, where $\varepsilon a$ is the axial strain, $q$ is the deviator stress and $\varepsilon v$ is the volumetric strain. It is found that the repeatability of experimental results for FRS was only obtained with the adoption of a certain number of layers (Mandolini, 2011; Mandolini et al., 2019). This is because segregation of fibres may happen within a thick layer, leading to sample inhomogeneity and leaving unreinforced bands within the sample. For the present study, it is found that good result repeatability can be achieved with three layers.

Figs. 6 and 7 show the effect of sample preparation methods on the stress-strain relationship of pure sand. In most cases, a small difference in the $\varepsilon a-q$ and $\varepsilon a-\varepsilon v$ curves can be observed for pure sand. But the sample preparation method has been found to have a more dramatic influence on the stress-strain relationship of sand in undrained tests (Sze and Yang, 2014) because a small difference in the soil dilatancy can cause a significant change in the effective stress path of an undrained test. Were these samples tested in undrained conditions, a more significant difference in the stress-strain relationship would be expected. A direct 
122 comparison of the behaviour of sand and FRS is shown in Figs. 8 and 9. At the same initial

123 void ratio and confining pressure, FRS shows much higher shear strength and less volume 124 expansion.

Table 3: List of tests

\begin{tabular}{|c|c|c|c|c|}
\hline Test ID & $\begin{array}{c}\text { Preparation } \\
\text { method }\end{array}$ & $w f(\%)$ & $e 0$ & $\sigma r(\mathrm{kPa})$ \\
\hline CD50_M_080 & \multirow{11}{*}{ MT } & \multirow{6}{*}{ - } & 0.803 & 50 \\
\hline CD100_M_080 & & & 0.808 & \multirow{2}{*}{100} \\
\hline CD100_M_075 & & & 0.761 & \\
\hline CD200_M_080 & & & 0.817 & \multirow{3}{*}{200} \\
\hline CD200_M_080_01 & & & 0.811 & \\
\hline CD200_M_075 & & & 0.756 & \\
\hline CD50_M_080_025 & & \multirow{5}{*}{0.25} & 0.811 & 50 \\
\hline CD100_M_080_025 & & & 0.823 & \multirow{2}{*}{100} \\
\hline CD100_M_075_025 & & & 0.762 & \\
\hline CD200_M_080_025 & & & 0.806 & \multirow{2}{*}{200} \\
\hline CD200_M_075_025 & & & 0.773 & \\
\hline CD50_D_080 & \multirow{9}{*}{ MV } & \multirow{5}{*}{ - } & 0.815 & 50 \\
\hline CD100_D_080 & & & 0.812 & \multirow{2}{*}{100} \\
\hline CD100_D_075 & & & 0.758 & \\
\hline CD200_D_080 & & & 0.803 & 200 \\
\hline CD200_D_075 & & & 0.755 & $\angle 00$ \\
\hline CD100_D_080_025 & & \multirow{4}{*}{0.25} & 0.822 & \multirow{2}{*}{100} \\
\hline CD100_D_075_025 & & & 0.772 & \\
\hline CD200_D_080_025 & & & 0.806 & \multirow{2}{*}{200} \\
\hline CD200_D_075_025 & & & 0.761 & \\
\hline
\end{tabular}



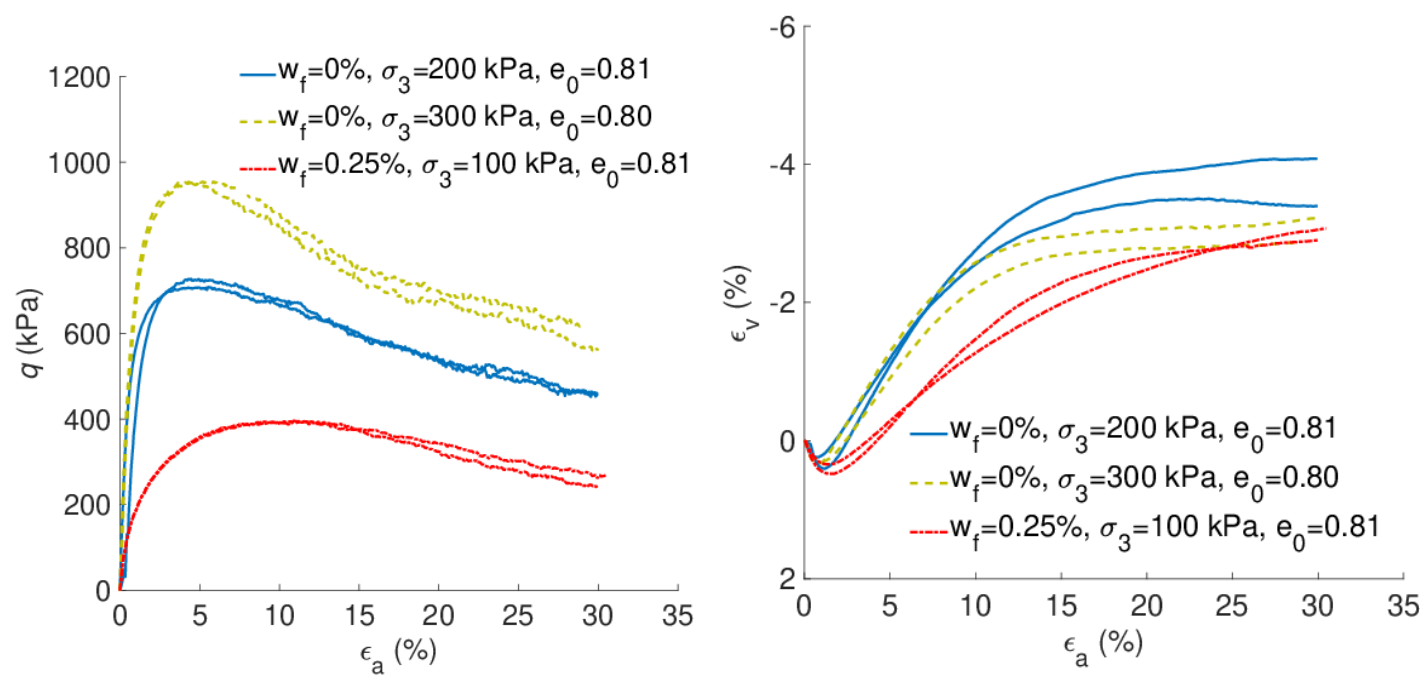

Fig. 4 Repeatability of the tests on MT samples with $\sigma r=-\mathrm{kPa}$ (a) the $\varepsilon a-q$ relationship
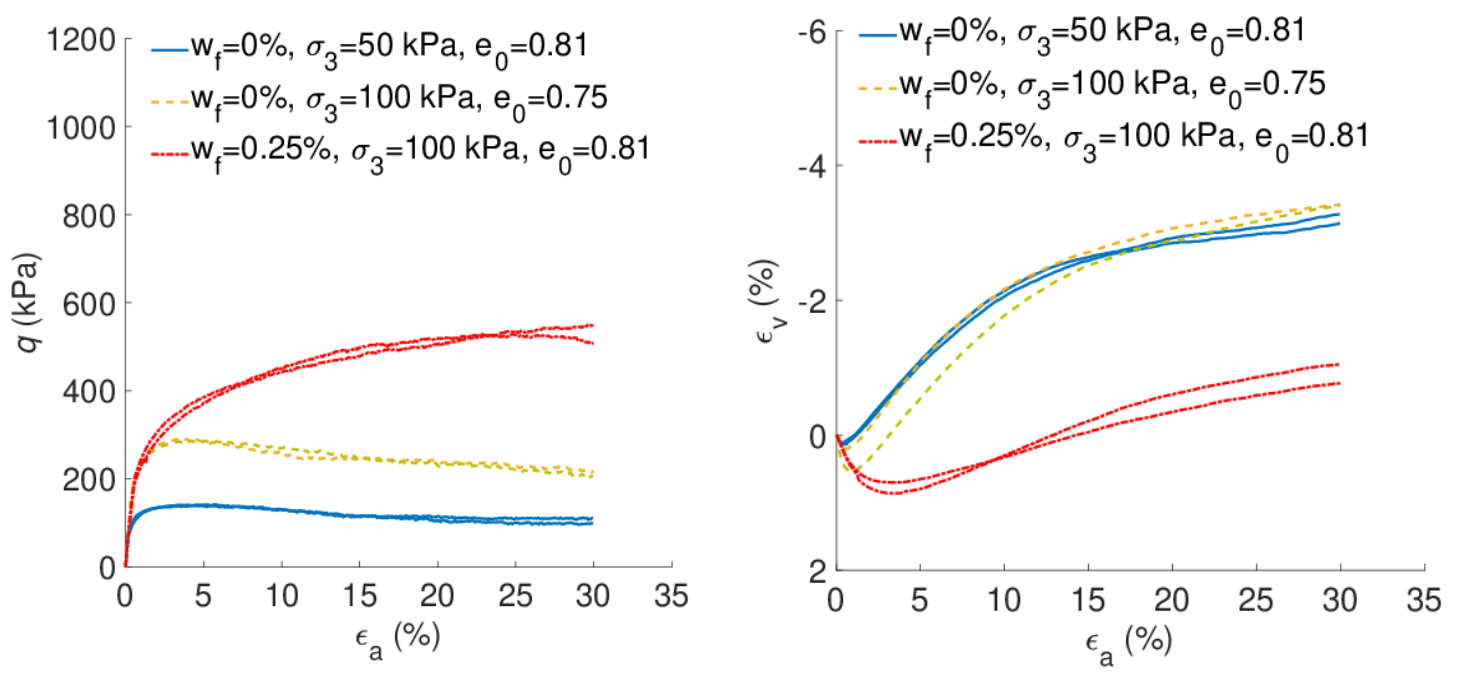

Fig. 5 Repeatability of the tests on MV samples with $\sigma r=-\mathrm{kPa}$ (a) the $\varepsilon a-q$ relationship and (b) the $\varepsilon a-\varepsilon v$ relationship 

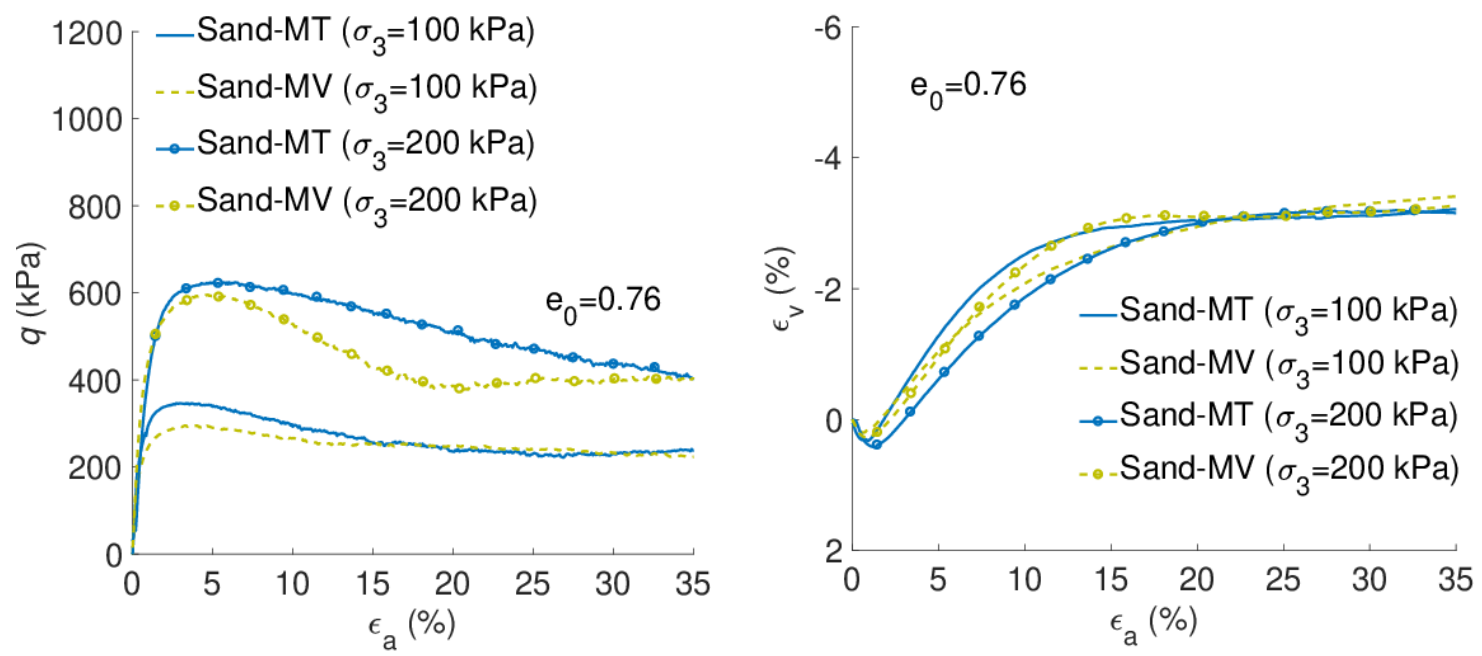

Fig. 6 Effect of the sample preparation method on mechanical behaviour of pure sand with : (a) $\varepsilon a-q$ relationship and (b) $\varepsilon a-\varepsilon v$ relationship
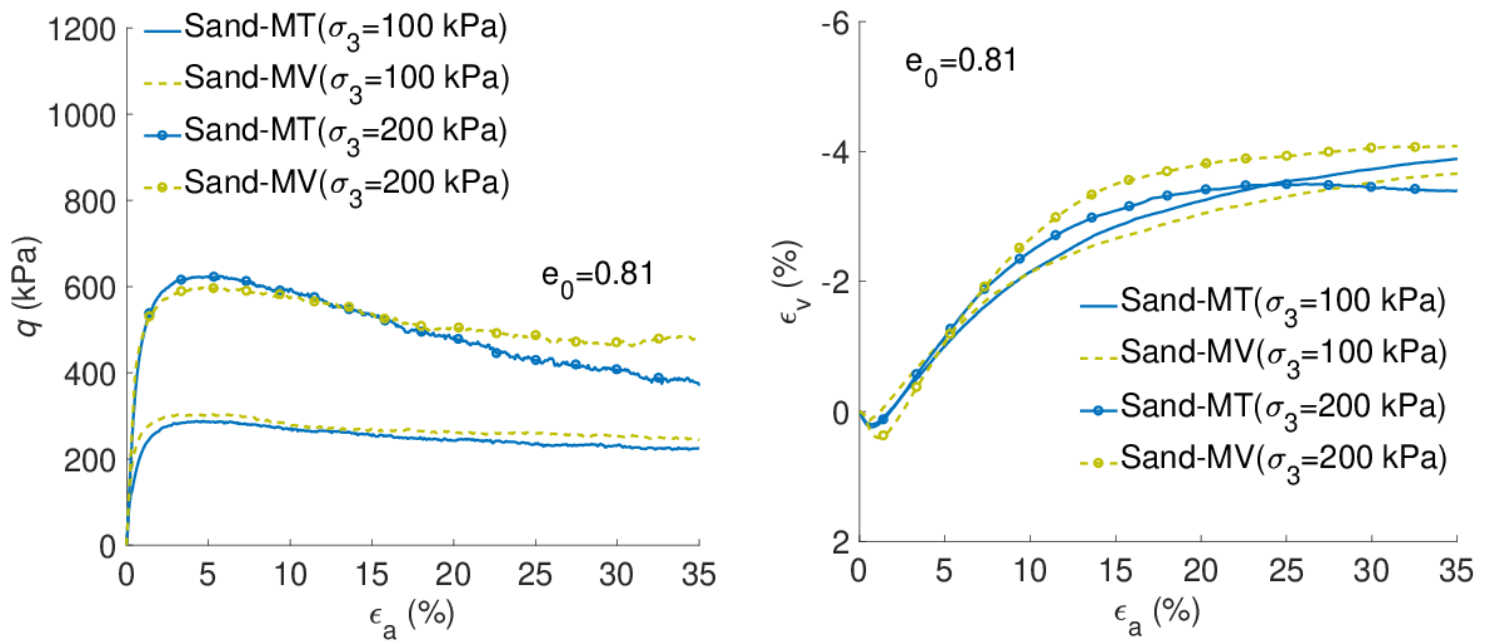

Fig. 7 Effect of the sample preparation method on the mechanical behaviour of pure sand with : (a) $\varepsilon a-q$ relationship and (b) $\varepsilon a-\varepsilon v$ relationship
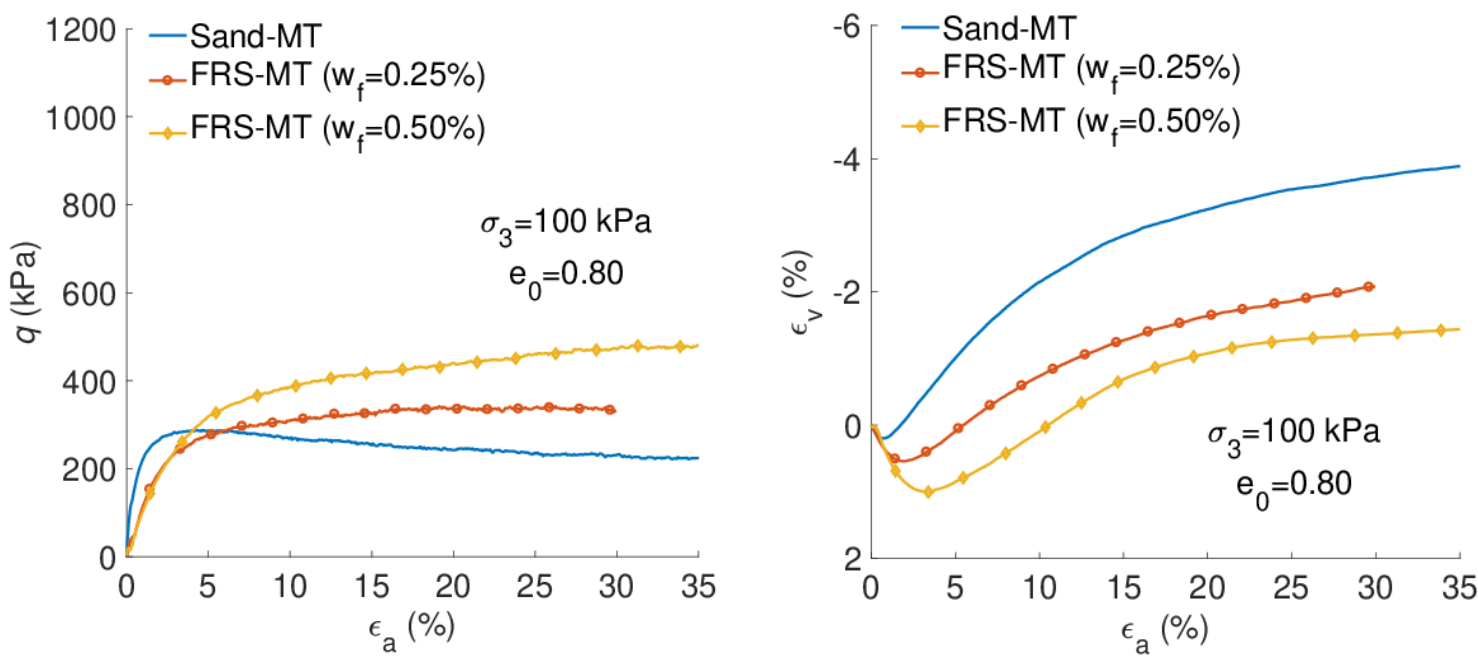

Fig.8 Effect of fibre content on the behaviour of fibre-reinforced sand prepared using the 

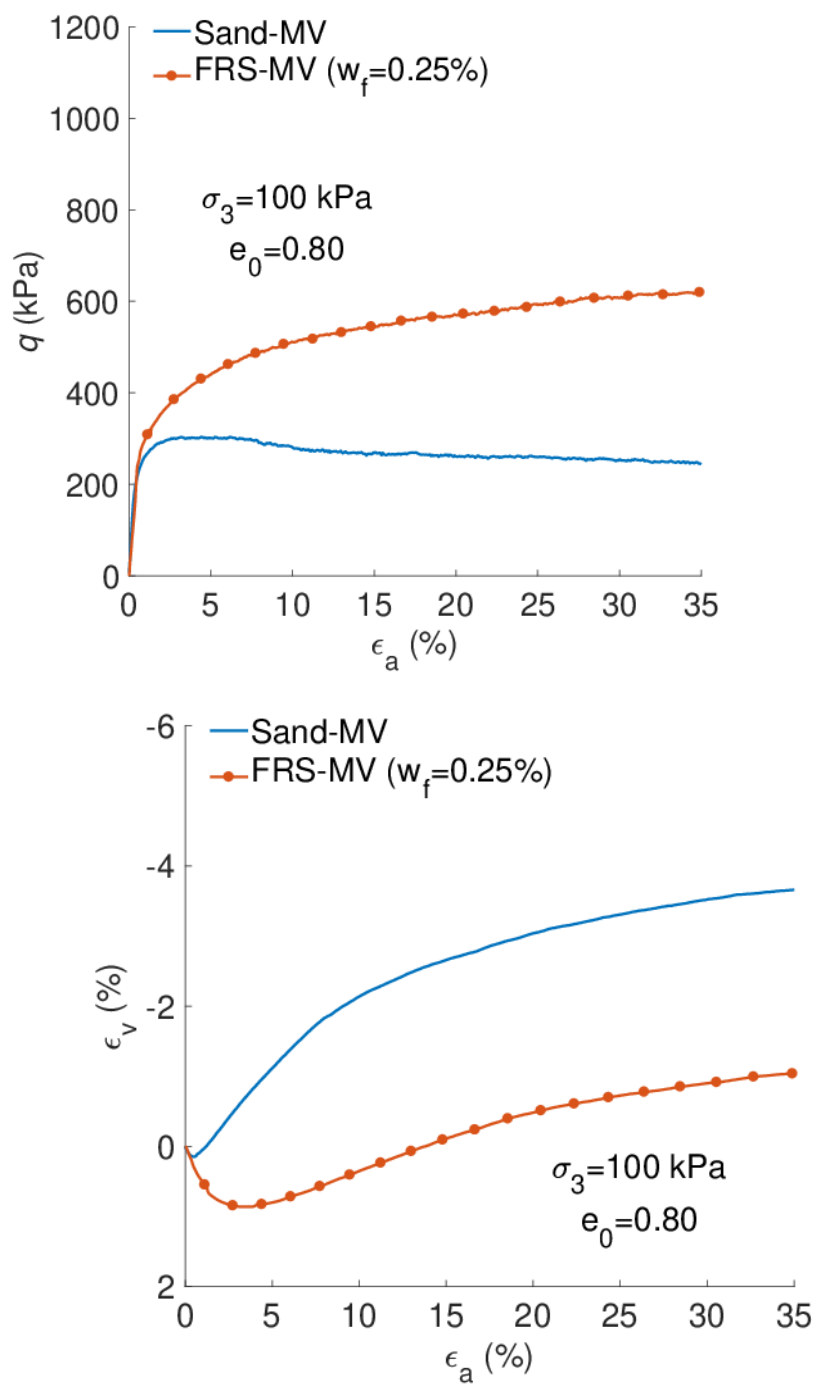

Fig. 9 Effect of fibre content on the behaviour of fibre-reinforced sand prepared using the

MV method: (a) $\varepsilon a-q$ relationship and (b) $\varepsilon a-\varepsilon v$ relationship

Figs. 10 and 11 show the stress-strain relationship of FRS with different sample preparation methods. There is significant difference in both the $\varepsilon a-q$ and $\varepsilon a-\varepsilon v$ relationships. Under the same initial condition, the MV samples show a less dilative response and much higher shear strength. The peak deviator stress of a MV sample is 30\%-50\% higher than that of the MT sample with the same initial stress state and void ratio. In particular, the ultimate strength for the MV sample with confining pressure of $100 \mathrm{kPa}$ is almost the same as that of the MT sample with confining pressure of $200 \mathrm{kPa}$ (Fig. 10). Most of the MV samples do not show 

relationship

strain softening at even very large axial strain. The shear stiffness of MV samples is also higher, indicating that the fibre-reinforcement to the soil stiffness and strength is more significant. This indicates that a method similar to the MV in this study should be used in compacting FRS in the field to achieve the largest possible increase in the soil strength.

Fig. 12 shows the failure envelope for FRS prepared using the MT and MV methods. It is well known that the failure envelope of FRS is curved, and the mobilized peak friction angle decreases as the mean effective stress increases (Diambra and Ibraim, 2015; Ibraim et al., 2012). Since all the tests have been carried out with the confining pressure over $100 \mathrm{kPa}$, the failure envelope of FRS at low mean effective stress cannot be obtained. Therefore, only the failure envelope with $p>150 \mathrm{kPa}$ is plotted in Fig. 12 . More tests should be done to get the failure curves at low mean effective stress. Prediction of the failure criterion proposed by Gao and Zhao (2013) is also shown in Fig. 12. Two parameters $c$ and $\kappa$ in this failure criterion will also be used in the constitutive model below.
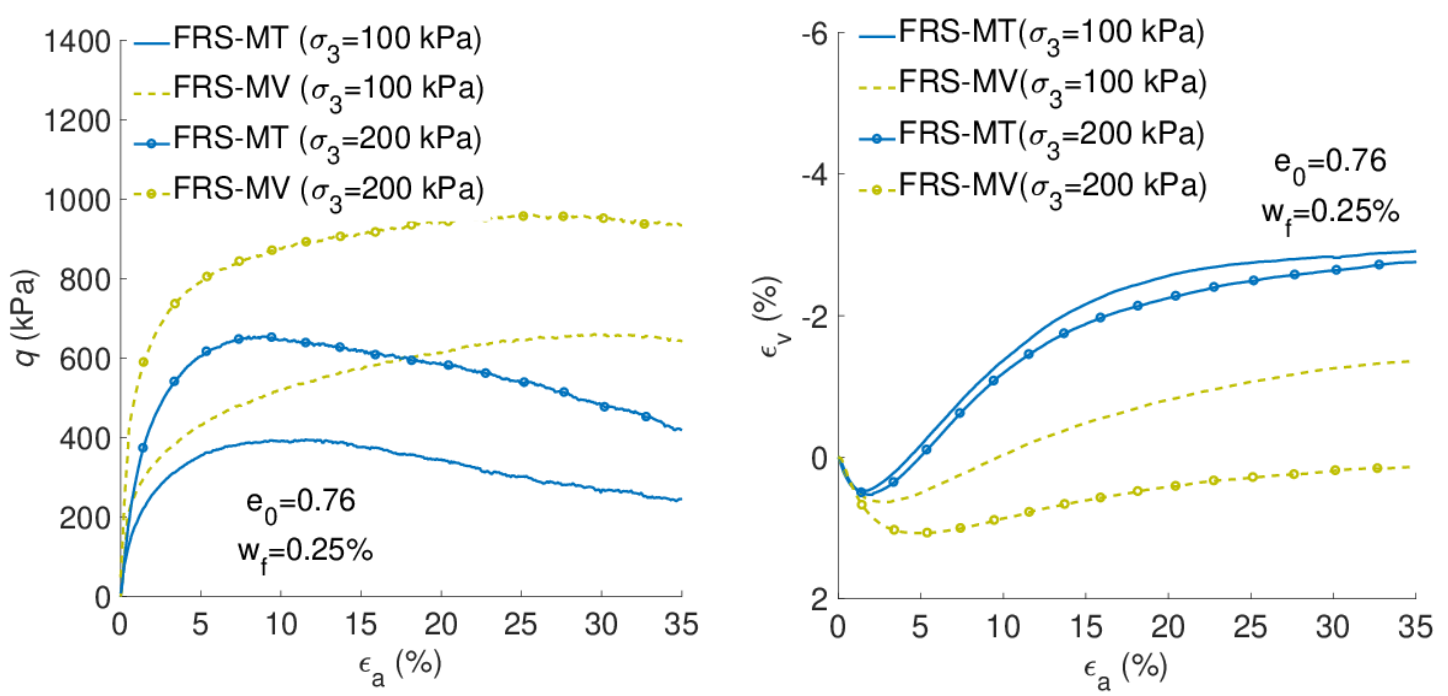

Fig. 10 The comparing results of FRS with different preparation methods under the confining pressure of 100 and $200 \mathrm{kPa}():$ (a) the $\varepsilon a-q$ relationship and (b) the $\varepsilon a-\varepsilon v$ 

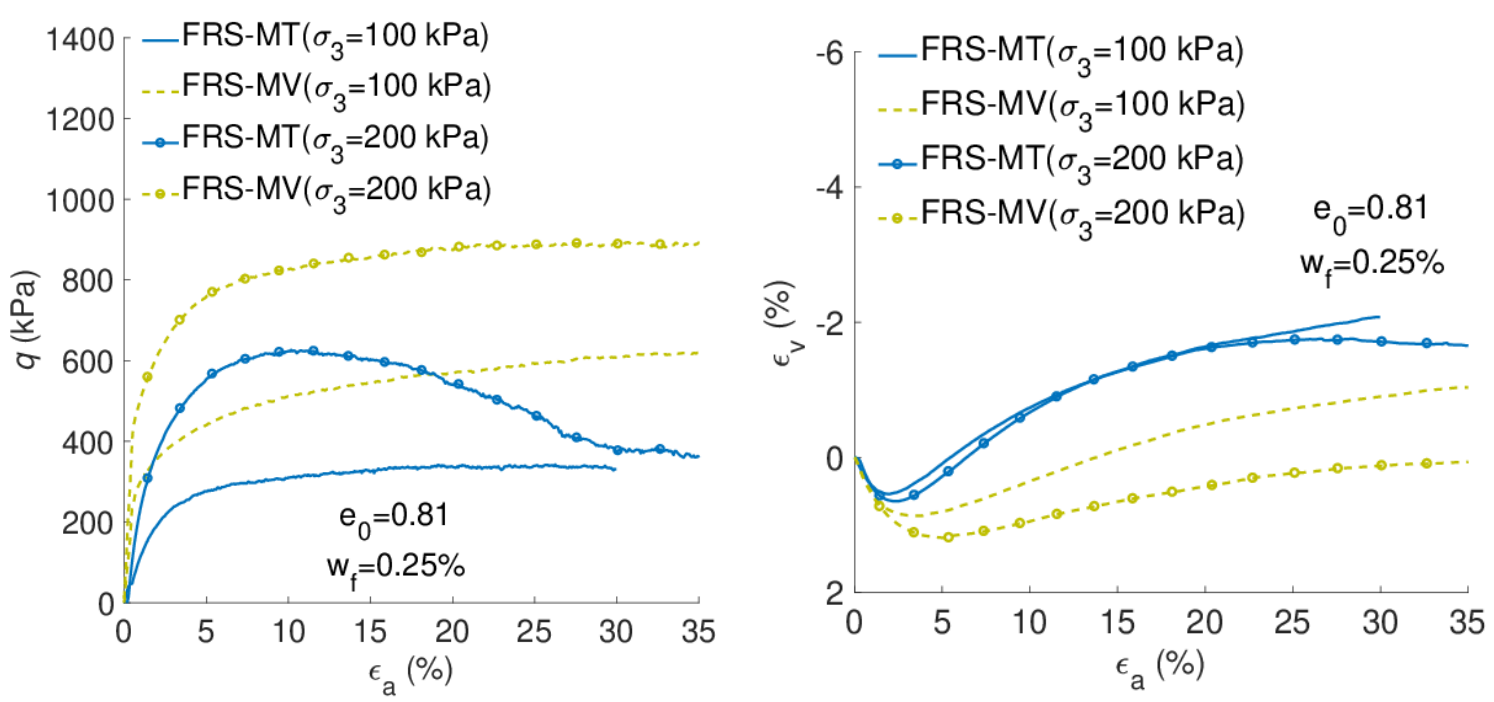

Fig. 11 The comparing results of FRS with different preparation methods under the confining pressure of 100 and $200 \mathrm{kPa} \mathrm{():} \mathrm{(a)} \mathrm{the} \varepsilon a-q$ relationship and (b) the $\varepsilon a-\varepsilon v$ relationship

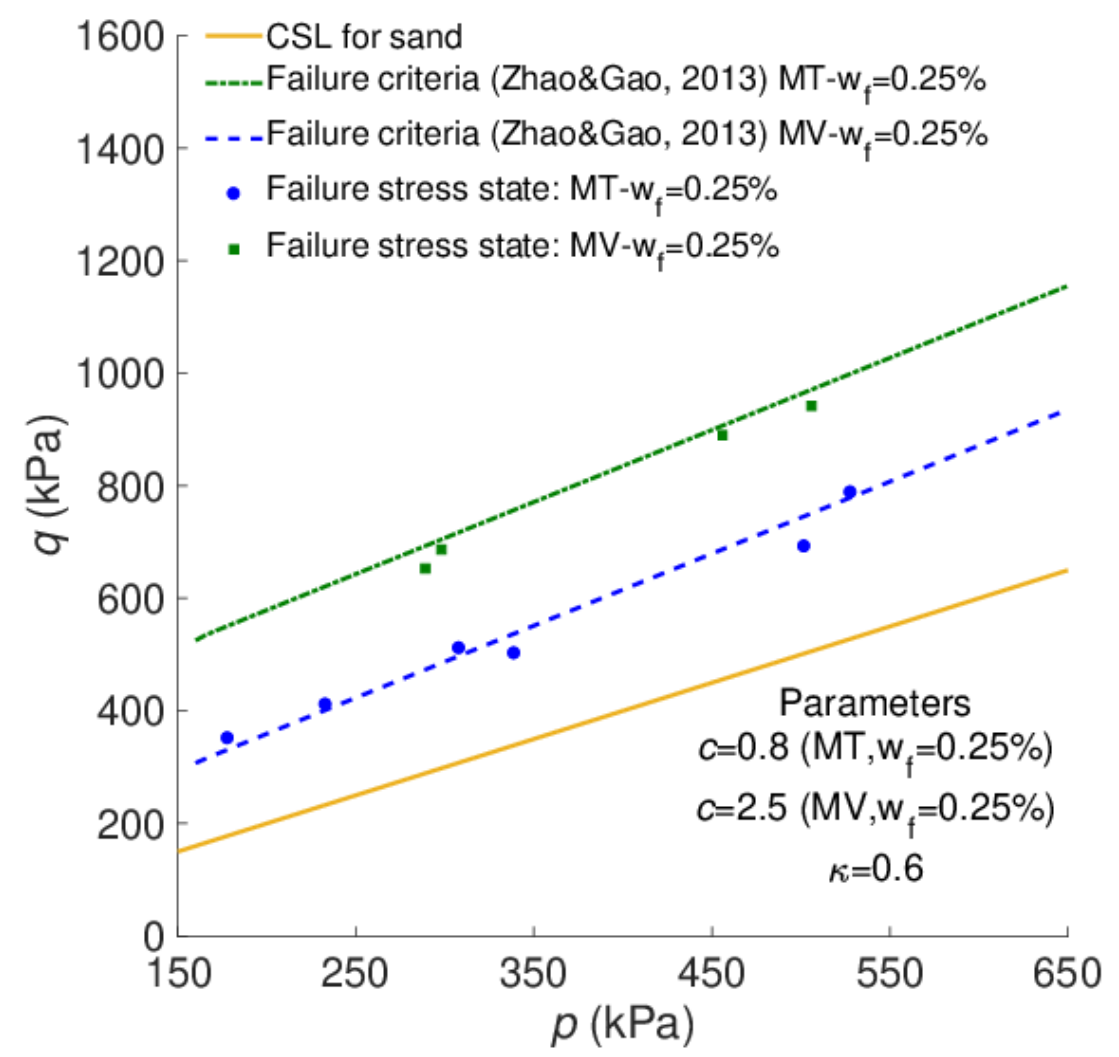

Fig. 12 The failure envelopes of FRS and prediction of the failure criterion proposed by Gao and Zhao (2013) 
The results in Figs. 10 and 11 are different from those in Ibraim et al. (2012), where a small difference in the behaviour of MT and MV samples has been observed. While the MT method in the present study is similar to that used in Ibraim et al. (2012), the MV method is different. First, only $2 \%$ of water content is used during sample preparation in this study, compared to $10 \%$ in Ibraim et al. (2012). Secondly, the sample is densified by tamping the side of the mould with a fixed vertical loading on top of the soil in this present study. But dynamic compaction in the vertical direction is used in Ibraim et al. (2012). Both the initial water content and compaction method can affect the fibre orientation, which affects the mechanical behaviour of FRS. Unfortunately, the fibre distribution in FRS has not been measured in the present study. Future work will be done to measure how the MT and MV methods used in this study affect the fibre orientation distribution using the method proposed by Ibraim et al. (2012). Thirdly, more fibres could be under tension at the end of sample preparation when the samples are prepared using the MV method in this study, as discussed in Consoli et al. (2005). This has a beneficial effect on the strength of FRS.

\section{Constitutive modelling}

Though the internal structure of FRS is affected by the fabric of both the sand skeleton and the fibres, the experimental evidence above shows that its mechanical behaviour is primarily affected by the fabric associated with the fibres. Therefore, a constitutive model for FRS can neglect the fabric of the sand skeleton (Ibraim et al., 2012). The model used in this study is developed based on the assumption that the strain of FRS is dependent on the deformation of the sand skeleton, while the effective skeleton stress ( $p s$ and $q s$ ) and effective skeleton void ratio es, which are used for describing the mechanical response of FRS (dilatancy, plastic hardening and elastic stiffness), are affected by fibre inclusion. Detailed discussions of the model have been presented in Gao et al. (2020) and Gao and Diambra (2020). Some key equations are presented here to facilitate the discussion in this study.

\section{$\underline{3.1 \text { Effective skeleton stress and void ratio }}$}

The effective skeleton stresses $p s$ and $q s$ are defined as (Gao et al., 2020) 
214 where $p$ and $q$ are the mean stress and deviatoric stress, respectively; $p f$ is a strain-level dependent variable which describes the fibre-reinforcement to the soil strength. $p f$ is assumed to vary from 0 at strain $\varepsilon q=0$ (negligible reinforcement to soil strength is expected when the fibres are not stretched) to $p c$ at a sufficiently large strain, with the evolution law

218 being expressed as

$$
d p f=\mu p c-p f 1+e p p a d \varepsilon q
$$
and $\varepsilon q$ is the shear strain. $p c$ is proposed based on the failure of FRS (Gao \& Zhao, 2013; Gao et al., 2020):

$$
p c=c p a 1-\exp (-\kappa p / p a)
$$

where $c$ and $\kappa$ are two extra parameters for modelling the strength of FRS. They are the same as those in the failure criterion proposed by Gao and Zhao (2013).

The effective skeleton void ratio es is expressed as

$$
e s=1+x \rho f e
$$
and dry sand, respectively. The variable $\rho f$ can be expressed in terms of the fibre weight content $w f$ as below (Gao et al., 2020), which is more frequently used in the existing 
235 where $G s$ and $G f$ denote the specific gravities of sand and fibres, respectively.

\subsection{Constitutive model}

237 The yield function of the model is (Li \& Dafalias, 2000)

$$
f=q p-H=0
$$

where $H$ is the hardening parameter and its evolution law is

$$
d H=L r H=L G 1-\zeta e s p s \eta s M c e-n \psi s-\eta s
$$

where $M c$ is the critical state stress ratio of sand; $\zeta$ and $n$ are two model parameters; $G$ is the elastic shear modulus of FRS; $\eta s(=q s p s)$ is the effective skeleton stress ratio.

The plastic flow rule is expressed as

$$
d \varepsilon q p=L
$$

and

$d \varepsilon v p=L D$

where $d \varepsilon q p$ and $d \varepsilon v p$ are the plastic deviatoric and plastic volumetric strain increment, respectively; $L$ is the loading index and are the Macauley brackets; ( $L=L$ for $L>0$ and for $L=0$ for $L \leq 0$ ); The dilatancy $D$ relation for FRS is

249 where $d$ and $m$ are two model paramters; $\psi s(=e s-e c s)$ is the state parameter for FRS, of which es and ecs are the current and critical state effective skeleton void ratio corresponding 
to the current $p s$, respectively (Been \& Jefferies, 1985). For pure sand, the state parameter is $\psi=e-e c$, where $e c=e \Gamma-\lambda c p p a \xi$. The critical state line in the $e s-p s$ plane has been given by Li \& Wang (1998)

where $e \Gamma, \lambda c$ and $\xi$ are three material constants, which should be determined using the test results of pure sand.

The empirical pressure-sensitive elastic moduli are employed for this model (Richart et al., 1970)

$$
e c s=e \Gamma-\lambda c p s p a \xi
$$

where $K$ is the elastic bulk modulus; $G 0$ is a material constant and $v$ is Poisson's ratio, which is considered as a material constant independent of pressure, density and fibre inclusion.

The full constitutive equation for the model is (Gao et al., 2020)

$$
d q d p=3 G 00 K-h L p r H+3 G-K \eta D 9 G 2-3 K G \eta 3 K G D-K 2 \eta D d \varepsilon q d \varepsilon v
$$

where $h L$ is the Heaviside function with $h L=1$ for $L>0$, and $h L=0$ otherwise.

There are 14 parameters used in this model, 11 of which are for the host sand (e.g., Li \& Dafalias, 2000). Since the sample preparation method is found to have a negligible influence on the behaviour of pure sand, the same parameters are used for sand prepared using MT and MV. The method for determining the sand parameters can be found in Li and Dafalias (2000). Once the model parameters for pure sand have been determined, the rest can be determined based on the triaxial compression test results on FRS (Gao et al., 2020). Specifically, the parameters $c$ and $\kappa$ should be determined based on the strength of FRS. $\mu$ 
273 should be determined to fit the shear stress and strain relationship of FRS. Finally, the 274 parameter $x$ can be obtained based on the dilatancy of FRS. All the model parameters are 275 listed in Table 4.

Table 4 Model parameters

\begin{tabular}{|c|c|c|c|}
\hline \multicolumn{2}{|c|}{ Parameters } & FRS (MT) & FRS (MV) \\
\hline \multirow{11}{*}{ Sand } & G0 & \multicolumn{2}{|c|}{150} \\
\hline & $v$ & \multicolumn{2}{|c|}{0.2} \\
\hline & $M c$ & \multicolumn{2}{|c|}{1.28} \\
\hline & $p a$ & \multicolumn{2}{|c|}{101} \\
\hline & $e \Gamma$ & \multicolumn{2}{|c|}{0.89} \\
\hline & $\lambda c$ & \multicolumn{2}{|c|}{0.010} \\
\hline & $\xi$ & \multicolumn{2}{|c|}{0.7} \\
\hline & $n$ & \multicolumn{2}{|c|}{2.0} \\
\hline & $\zeta$ & \multicolumn{2}{|c|}{0.8} \\
\hline & $d$ & \multicolumn{2}{|c|}{0.90} \\
\hline & $m$ & \multicolumn{2}{|c|}{1.8} \\
\hline \multirow{4}{*}{ FRS } & $x$ & 7.3 & 8.8 \\
\hline & $\kappa$ & 0.6 & 0.6 \\
\hline & $\mu$ & 6.0 & 9.0 \\
\hline & $c$ & 0.8 & 2.5 \\
\hline
\end{tabular}

$278 \quad 3.3$ The model simulations

279 Figs. 13-15 show the model prediction of pure sand behaviour. In general, the model gives a 
satisfactory description of the experimental data. There is a slight overestimation of the volume expansion in some tests (Fig. 15). Better model predictions can be obtained by using different model parameters for MT and dry deposited sand (Yang et al., 2008). This will inevitably make the model more complex, but may not improve the predictions for FRS, which is the focus of this study.

Figs. 16-19 show the comparison between test data and model prediction of FRS prepared using MT and MV. The model prediction is better for the MT samples. For the MV samples, the model tends to give lower deviator stress before failure. This could be due to the model not being able to describe the evolution of mean effective skeleton stress $p f$ with strain, which has also been discussed in Gao et al. (2020). The four parameters for FRS can be used to infer the difference in the internal structure of FRS (Table 5). The value of $x$ is bigger for FRS prepared using the MV method, which means that the effective skeleton void ratio es is higher for the MV samples when the fibre content and global void ratio are the same (Gao et al., 2020). This could be caused by the structure of the sand skeleton and distribution of fibres, which can be better understood using X-ray computed tomography studies (Soriano et al., 2017). The parameters $c$ and $\mu$ which describe the fibre reinforcement to soil strength and stiffness are also higher for the FRS prepared using the MV method. A larger $c$ means that a larger shear strength increase is achieved when the samples are prepared by the MV method (Figs. 16-19). A larger $\mu$ makes the shear stiffness of FRS higher, indicating faster development of the fibre-reinforcement. Both $c$ and $\mu$ are mainly affected by the distribution of fibre orientation in FRS (Ibraim et al., 2012). They are bigger when more fibres orient in the horizontal direction. However, in the study of Ibraim et al. (2012), it was shown that the different preparation methods did not produce a significantly different distribution of fibre orientation. A micromechanical study is thus needed to find out the reason for the difference in these parameters here. 

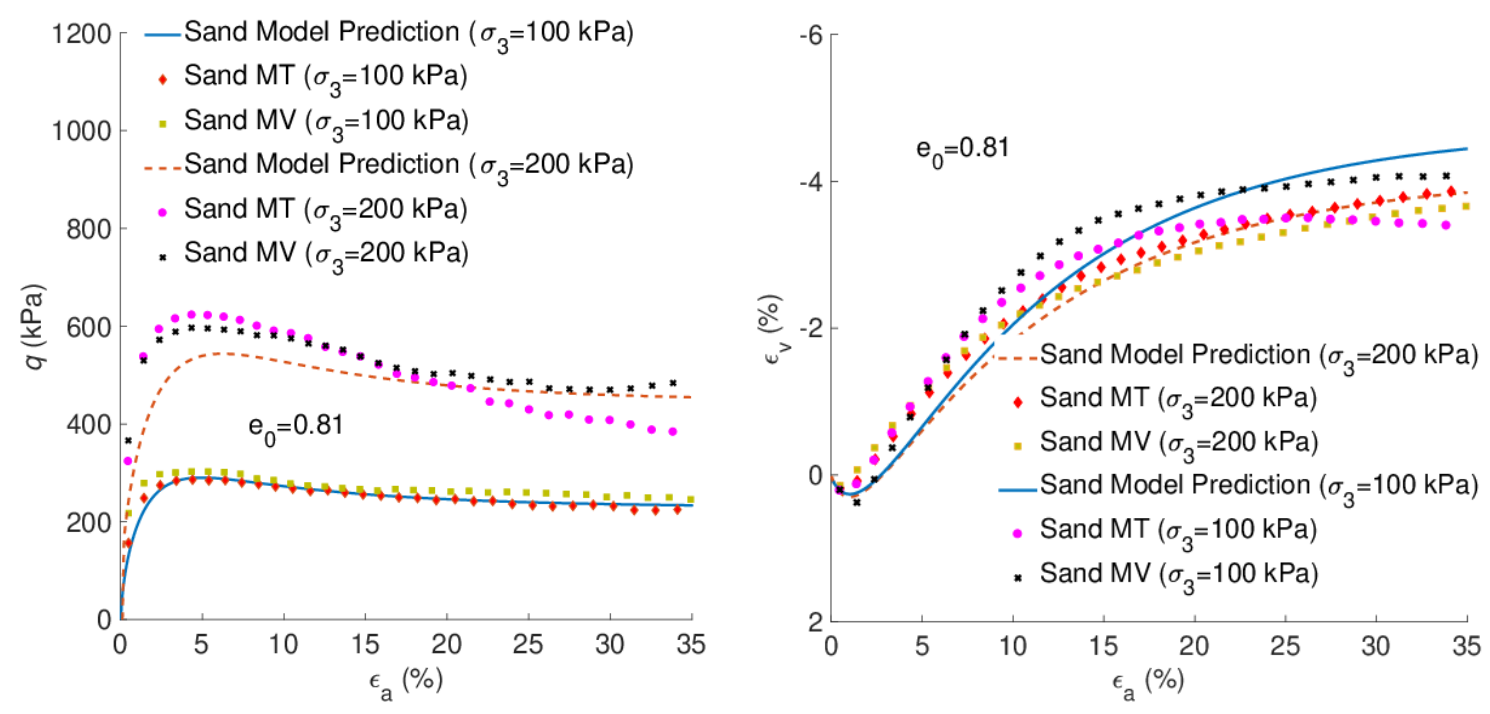

Fig. 13 Model prediction for the behaviour of pure sand in drained triaxial compression

with : (a) the $\varepsilon a-q$ relationship and (b) the $\varepsilon a-\varepsilon v$ relationship
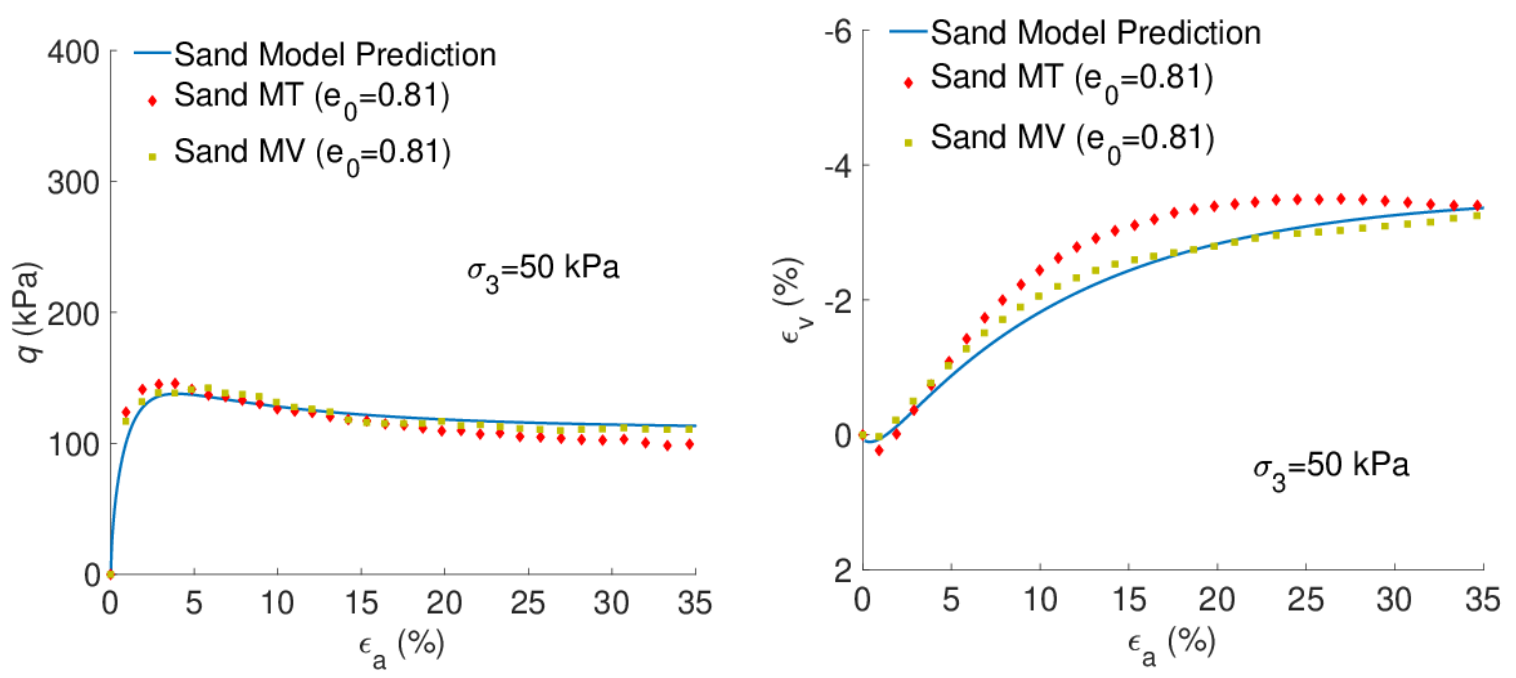

310 Fig. 14 Model prediction for the behaviour of pure sand in drained triaxial compression

311 with $\mathrm{kPa}$ and : (a) the $\varepsilon a-q$ relationship and (b) the $\varepsilon a-\varepsilon v$ relationship 

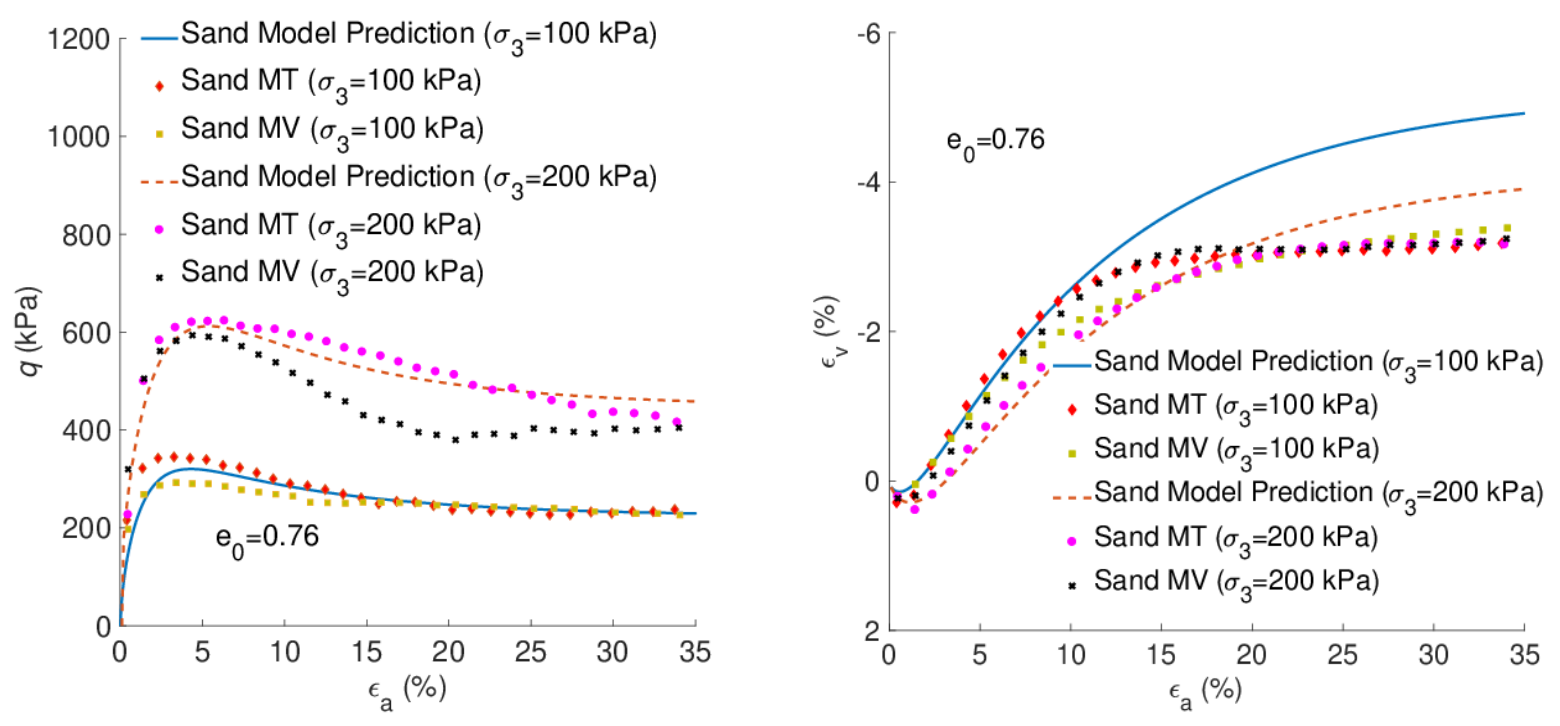

Fig. 15 Model prediction for the behaviour of pure sand in drained triaxial compression

with : (a) the $\varepsilon a-q$ relationship and (b) the $\varepsilon a-\varepsilon v$ relationship
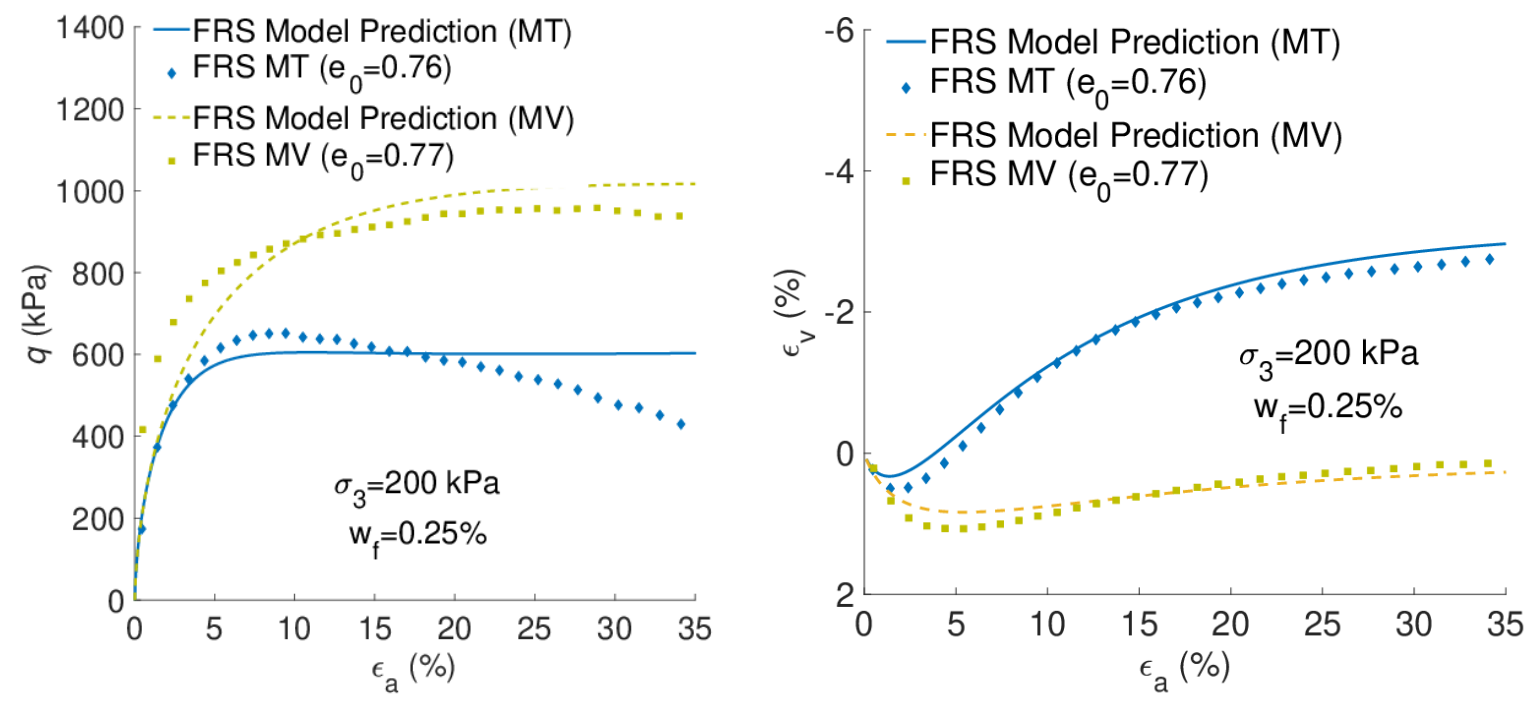

Fig. 16 Model prediction for the behaviour of FRS in drained triaxial compression with $\mathrm{kPa}$ 

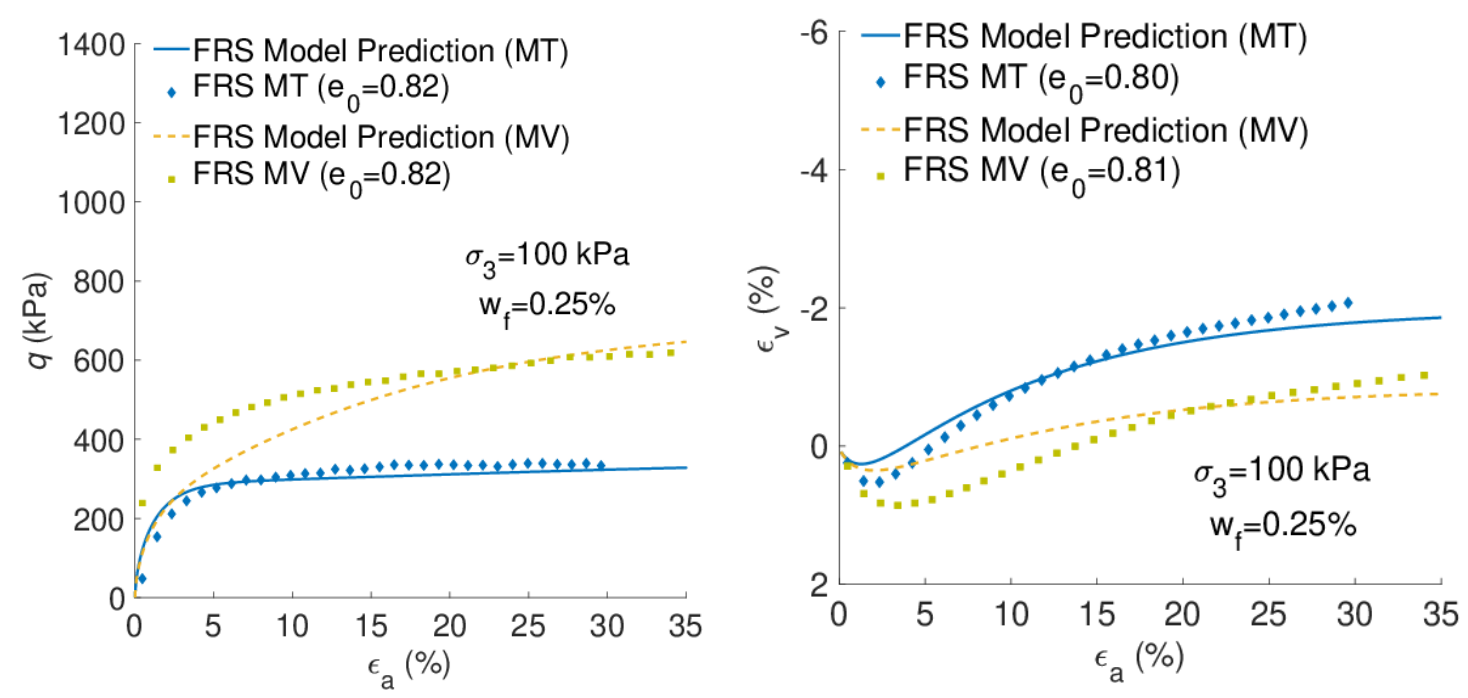

Fig. 17 Model prediction for the behaviour of FRS in drained triaxial compression with $\mathrm{kPa}$ and : (a) the $\varepsilon a-q$ relationship and (b) the $\varepsilon a-\varepsilon v$ relationship
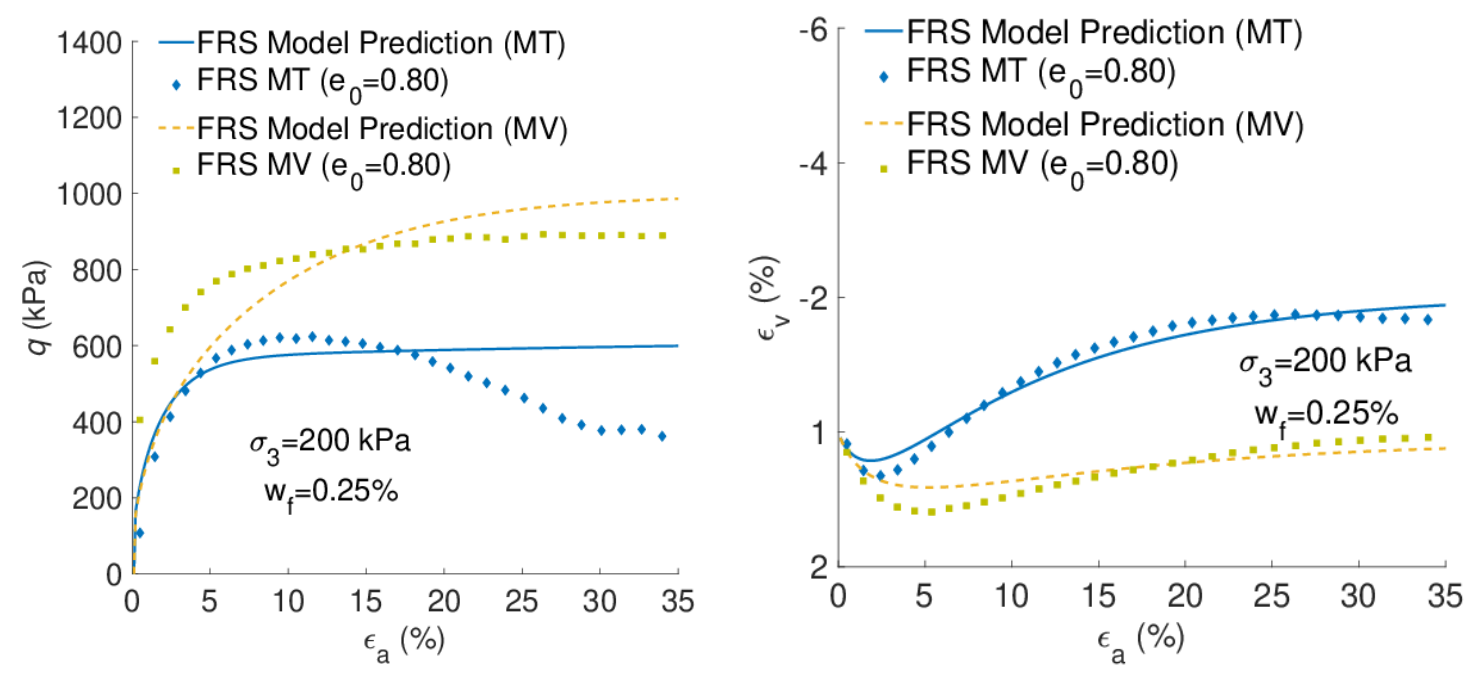

Fig. 18 Model prediction for the behaviour of FRS in drained triaxial compression with $\mathrm{kPa}$ 


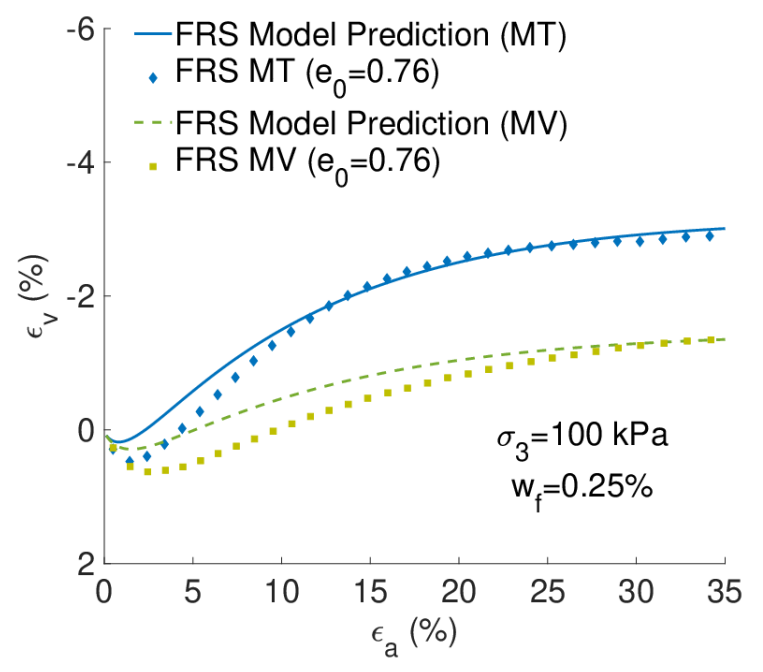

Fig. 19 Model prediction for the behaviour of FRS in drained triaxial compression with $\mathrm{kPa}$ and : (a) the $\varepsilon a-q$ relationship and (b) the $\varepsilon a-\varepsilon v$ relationship

\section{Conclusion}

The effect of sample preparation method on the mechanical behaviour of FRS has been studied using drained triaxial compression tests. The samples are prepared using MT and MV methods. The stress-strain relationship of pure sand appears to be insensitive to the sample preparation method. The mechanical behaviour of FRS is dramatically affected by the sample preparation methods, with the MV samples showing a less dilative response and higher shear strength under otherwise identical conditions. A newly developed constitutive model has been used to describe the stress-strain relationship of FRS. Some of the parameters for FRS have to be changed when the sample preparation method changes.

Future research will be done on the following aspects. Firstly, research will be done on the internal structure of FRS at the microscale (interaction between sand particles and fibres and fibre distribution) using both experimental and numerical studies. These studies will help us get a better understanding of how sample preparation methods affect the soil structure and stress-strain relationship. Additionally, the present research has focused on the mechanical behaviour of saturated sand and FRS. But the unsaturated condition can be of importance in the field, where the soil is subjected to drying and wetting cycles. Therefore, research will be done to find out how the capillary force caused by unsaturation affects the behaviour of FRS 
(Yao et al., 2009; Melnikov et al., 2016; Liu et al., 2020).

The experiments were carried out with the technical support of Mr Timothy Montgomery at the Soil Mechanics Lab of the University of Glasgow. The authors would like to acknowledge Dr Thomas Shire at the University of Glasgow for proofreading the manuscript.

\section{REFERENCES}

Ahmad F, Bateni F, Azmi M. Performance evaluation of silty sand reinforced with fibres. Geotextile and Geomembranes 2010. https://doi.org/10.1016/j.geotexmem.2009.09.017.

Been K, Jefferies MG. A state parameter for sands. Geotechnique 1985. https://doi.org/10.1680/geot.1985.35.2.99.

Bower, T. Recovering together: Constitutive modelling of soils and fibre-reinforced soils. Doctoral dissertation. Cardiff University, 2017.

Consoli NC, Festugato L, Heineck KS. Strain-hardening behaviour of fibre-reinforced sand in view of filament geometry. Geosynth Int 2009. https://doi.org/10.1680/gein.2009.16.2.109.

362 Consoli NC, Heineck KS, Casagrande MDT, Coop MR. Shear strength behavior of 363 fiber-reinforced sand considering triaxial tests under distinct stress paths. J Geotech https://doi.org/10.1061/(ASCE)1090-0241(2007)133:11(1466).

Consoli NC, Casagrande MDT, Coop MR. Effect of fiber reinforcement on the isotropic 367 compression behavior of a sand. J Geotech Geoenvironmental Eng 2005. https://doi.org/10.1061/(ASCE)1090-0241(2005)131:11(1434).

369 Diambra A, Ibraim E. Fibre-reinforced sand: Interaction at the fibre and grain scale. Geotechnique 2015. https://doi.org/10.1680/geot.14.P.206. 
Diambra A, Russell AR, Ibraim E, Wood DM. Determination of fibre orientation distribution in reinforced sands. Geotechnique 2007. https://doi.org/10.1680/geot.2007.57.7.623.

Gao Z, Diambra A. A multiaxial constitutive model for fibre-reinforced sand. Géotechnique 2020. https://doi.org/10.1680/jgeot.19.p.250.

Gao Z, Lu D, Huang M. Effective skeleton stress and void ratio for constitutive modeling of fiber-reinforced sand. Acta Geotech 2020. https://doi.org/10.1007/s11440-020-00986-w.

Gao Z, Zhao J. Evaluation on failure of fiber-reinforced sand. J Geotech Geoenvironmental Eng 2013. https://doi.org/10.1061/(ASCE)GT.1943-5606.0000737.

Ibraim E, Diambra A, Russell AR, Muir Wood D. Assessment of laboratory sample preparation for fibre reinforced sands. Geotext Geomembranes 2012. https://doi.org/10.1016/j.geotexmem.2012.03.002.

Ishihara K. Liquefaction and flow failure during earthquakes. Geotechnique 1993. https://doi.org/10.1680/geot.1993.43.3.351.

Kong Y, Zhou A, Shen F, Yao Y. Stress-dilatancy relationship for fiber-reinforced sand and its modeling. Acta Geotech 2019. https://doi.org/10.1007/s11440-019-00834-6.

Li XS, Dafalias YF. Dilatancy for cohesionless soils. Geotechnique 2000. https://doi.org/10.1680/geot.2000.50.4.449.

Li XS, Wang Y. Linear representation of steady-state line for sand. J Geotech Geoenvironmental Eng 1998. https://doi.org/10.1061/(ASCE)1090-0241(1998)124:12(1215).

Liu X, Zhou A, Shen S long, Li J, Sheng D. A micro-mechanical model for unsaturated soils based on DEM. Comput Methods Appl Mech Eng 2020;368. https://doi.org/10.1016/j.cma.2020.113183.

Mandolini A, Diambra A, Ibraim E. Strength anisotropy of fibre-reinforced sands under multiaxial loading. Geotechnique 2019. https://doi.org/10.1680/igeot.17.P.102. 
Mandolini A. Recovering Together: Investigation of strength anisotropy of fibre reinforced sands under generalised loading conditions using the HCTA. MSc by Research thesis, University of Bristol, 2011.

Melnikov K, Wittel FK, Herrmann HJ. Micro-mechanical failure analysis of wet granular matter. Acta Geotech 2016. https://doi.org/10.1007/s11440-016-0465-5.

Michalowski RL. Limit analysis with anisotropic fibre-reinforced soil. Geotechnique 2008. https://doi.org/10.1680/geot.2008.58.6.489.

Michalowski RL, Čermák J. Strength anisotropy of fiber-reinforced sand. Comput Geotech 2002. https://doi.org/10.1016/S0266-352X(01)00032-5.

Michalowski, R. L. Micromechanics-based failure model of granular/particulate medium with reinforcing fibers. Air Force office of Scientific Research, USA. 1996.

Muir Wood D, Diambra A, Ibraim E. Fibres and soils: A route towards modelling of root-soil systems. Soils Found 2016. https://doi.org/10.1016/j.sandf.2016.08.003.

Richart Jr. FE, Hall Jr. JR, Woods RD. Vibrations of Soils and Foundations. 1970.

Santoni RL, Webster SL. Airfields and roads construction using fiber stabilization of sands. J Transp Eng 2001. https://doi.org/10.1061/(ASCE)0733-947X(2001)127:2(96).

Senetakis K, Li H. Influence of stress anisotropy on small-strain stiffness of reinforced sand with polypropylene fibres. Soils Found 2017. https://doi.org/10.1016/j.sandf.2017.07.003.

Senetakis K, Li H. Influence of stress anisotropy on small-strain stiffness of reinforced sand $\begin{array}{lllll}\text { with polypropylene fibres. Soils } & \text { Found }\end{array}$ https://doi.org/10.1016/j.sandf.2017.07.003.

Soriano I, Ibraim E, Andò E, Diambra A, Laurencin T, Moro P, et al. 3D fibre architecture of fibre-reinforced sand. Granul Matter 2017. https://doi.org/10.1007/s10035-017-0760-3. 
418 Sze HY, Yang J. Failure modes of sand in undrained cyclic loading: Impact of sample

419 preparation. J Geotech Geoenvironmental Eng 2014.

420 https://doi.org/10.1061/(ASCE)GT.1943-5606.0000971.

421 Yang ZX, Lit XS, Yang J. Quantifying and modelling fabric anisotropy of granular soils.

422 Geotechnique 2008. https://doi.org/10.1680/geot.2008.58.4.237.

423 Yao YP, Hou W, Zhou AN. UH model: Three-dimensional unified hardening model for 424 overconsolidated clays. Geotechnique 2009. https://doi.org/10.1680/geot.2007.00029.

425 Zhao J, Gao Z. Unified anisotropic elastoplastic model for sand. J Eng Mech 2016. 426 https://doi.org/10.1061/(ASCE)EM.1943-7889.0000962.

427 Zornberg JG. Discrete framework for limit equilibrium analysis of fibre-reinforced soil. 428 Geotechnique 2002. https://doi.org/10.1680/geot.2002.52.8.593. 